\title{
Identification of a Monogenic Locus (jams1) Causing Juvenile Audiogenic Seizures in Mice
}

\author{
Hidemi Misawa, ${ }^{*}$ Elliott H. Sherr, ${ }^{1,2 *}$ David J. Lee, ${ }^{1}$ Dane M. Chetkovich, ${ }^{1,2}$ Andrew Tan, ${ }^{1,3}$ \\ Christoph E. Schreiner, ${ }^{1,3}$ and David S. Bredt ${ }^{1}$ \\ Departments of ${ }^{1}$ Physiology, ${ }^{2}$ Neurology, and ${ }^{3}$ Otolaryngology, University of California at San Francisco, \\ School of Medicine, San Francisco, California 94143-0444
}

Epilepsy is a debilitating disease with a strong genetic component. Positional cloning has identified a few genes for rare monogenic epilepsy syndromes; however, the genetics of common human epilepsies are too complex to be analyzed easily by current techniques. Mouse models of epilepsy can further this analysis by eliminating genetic background heterogeneity and enabling the production of sufficient numbers of offspring. Here, we report that Black Swiss mice have a heretofore unrecognized specific susceptibility to audiogenic seizures. These seizures are characterized by wild running, loss of righting reflex, and tonic flexion and extension, and are followed by a postictal period. The susceptibility to these seizures is developmentally regulated, peaking at $21 \mathrm{~d}$ of age and nearly disappearing by adulthood. Interestingly, both the susceptibility to seizures and their developmental regulation appear unrelated to hearing

Epilepsy, or the predisposition to recurrent seizures, profoundly affects $1-2 \%$ of the population, primarily the young. Seizures can result from hypersynchronized firing of neurons and often occur without structural or other neurological abnormalities. Patients with both primary generalized and temporal lobe epilepsy frequently have a positive family history for seizures, although few human epilepsy syndromes are inherited in a simple Mendelian manner (Ryan, 1999). This complexity has precluded the discovery of genes responsible for common forms of epilepsy. In contrast, genes responsible for certain rare monogenic epilepsy syndromes, such as benign familial neonatal convulsions, autosomal dominant nocturnal frontal lobe epilepsy, and generalized epilepsy with febrile seizures plus have been cloned recently (Prasad et al., 1999).

Mouse models of seizure susceptibility provide an additional strategy for understanding the genetic basis of epilepsy. This offers the advantage of many well characterized strains and the

\footnotetext{
Received June 19, 2002; revised Aug. 23, 2002; accepted Sept. 6, 2002.

This work was supported by grants (D.S.B.) from the National Institutes of Health and the Howard Hughes Medical Institute (HHMI) Research Resources Program (D.S.B.). E.H.S. is supported by a Neurological Sciences Academic Development Award from the National Institute of Neurological Disorders and Stroke. H.M. was supported by a fellowship grant from the Human Frontier Science Program. D.M.C. was a postdoctoral fellow of the HHMI. D.S.B is an established investigator for the American Heart Association. We thank Drs. Larry Tecott and Allan Balmain for their input throughout the development of this work.

${ }^{*}$ H.M. and E.H.S. contributed equally to this work.

Correspondence should be addressed to David S. Bredt, University of California at San Francisco School of Medicine, 513 Parnassus Avenue, San Francisco, CA 94143-0444. E-mail: bredt@itsa.ucsf.edu.

H. Misawa's present address: Department of Neurology, Tokyo Metropolitan Institute for Neuroscience 2-6, Musashidai, Fuchu City, Tokyo 183-8526, Japan. Copyright (C) 2002 Society for Neuroscience $0270-6474 / 02 / 2210088-06 \$ 15.00 / 0$
}

thresholds in the Black Swiss strain and backcrossed progeny. Genetic mapping and linkage analysis of hybrid mice localize the seizure gene, jams1 (juvenile audiogenic monogenic seizures), to a $1.6 \pm 0.5$ centimorgan (cM) region on mouse chromosome 10, delimited by the gene basigin (Bsg) and marker D10Mit140. Interestingly, the majority of the critical region is syntenic to a region on human chromosome 19p13.3 implicated in a familial form of juvenile febrile convulsions. Cloning the gene for audiogenic seizures in these mice may provide important insight into the fundamental mechanisms for developmentally regulated human epilepsy syndromes.

Key words: mouse audiogenic seizures; chromosome 10; febrile seizures; chromosome 19p13.3; genetics; developmental regulation; auditory brainstem evoked response

capacity to breed sufficient offspring for genetic analyses. Both monogenic and polygenic seizure disorders occur in mice, and several spontaneously occurring epileptogenic mutations have now been identified. These have occurred primarily in genes encoding ion channels (Noebels, 1999). However, many of these mutants have ataxia and evidence of neuronal degeneration, features not found in most patients with idiopathic generalized epilepsy (Ryan, 1999).

One of the best-studied mouse models of generalized epilepsy is susceptibility to audiogenic seizures. These seizures occur reproducibly on exposure to a noxious sound and may be induced by other sensory stimuli. Audiogenic seizures were first observed $>75$ years ago by Pavlov (Brennan et al., 1997) and by investigators at the Wistar Institute (Ross and Coleman, 2000). The fact that susceptibility to audiogenic seizures can be inherited and varies markedly between strains has been recognized for $>50$ years (Hall, 1947; Seyfried et al., 1999). Understanding the genetics of audiogenic seizures has the potential to add important insight into the mechanisms of generalized seizure disorders. The genetics of audiogenic seizures in the mouse strain DBA/2J have been studied extensively, and three seizure susceptibility loci have been mapped to chromosomes 4, 7, and 12 (Neumann and Seyfried, 1990). However, each locus confers only a small percentage of the susceptibility, and the inheritance from at least one locus is complicated by genomic imprinting (Banko et al., 1997). A very recent study described the cloning of a previously uncharacterized gene, mass1, on chromosome 13 that is responsible for audiogenic seizures in the Frings mouse (Skradski et al., 2001).

Here, we report that Black Swiss (BS) mice are highly sensitive to audiogenic seizures and that this susceptibility is age depen- 
dent. Moreover, we found that the developmental regulation of these seizures does not correlate genetically with hearing thresholds in juveniles or with changes in thresholds as adults. This trait is inherited in a simple autosomal recessive manner, and genetic mapping links the disease gene to a 1.6 centimorgan $(\mathrm{cM})$ region on mouse chromosome 10. Cloning the gene for audiogenic seizures in Black Swiss mice may provide important insight into fundamental mechanisms for human developmental epilepsy syndromes.

\section{MATERIALS AND METHODS}

Animals. Black Swiss mice (Tac:N:NIHS-BC; Taconic, Germantown, NY) were derived from National Institutes of Health Swiss and C57BL/6 mice. These mice have subsequently been maintained as a closed colony. All markers tested across chromosome 10 have been homozygous for the $>100$ Black Swiss mice used in these experiments (data not shown). Adult 129S1/SvImJ (129) and CAST/Ei mice were obtained from The Jackson Laboratory (Bar Harbor, ME). Procedures for generating MALS-1 (mammalian homolog of Lin-7; Veli1)-null mutant mice have been described previously (Misawa et al., 2001). Briefly, a portion of $M A L S$ - 1 gene was deleted by homologous recombination in embryonic stem (ES) cells (derived from 129S1/SvImJ). Chimeric mice from the targeted ES cells were mated with Black Swiss mice to generate heterozygous $F_{1}$ mice. The heterozygotes were intercrossed to generate $F_{2}$ mice or backcrossed onto Black Swiss mice to create $\mathrm{N}_{2}$ progeny.

Audiogenic seizure induction. The procedure and apparatus used for audiogenic stimulation are essentially the same as described previously (Brennan et al., 1997). Mice were placed individually in a sound box and received a $108 \mathrm{~dB}$ auditory stimulus, which was a mixture of four pure tones $(5,11,15$, and $19 \mathrm{kHz})$ for 1 min or until an overt seizure. For purposes of genetic analysis, wild running and/or seizures were scored equivalently, and only the response to the first acoustic stimulation was included in the genetic analysis.

Drug-induced seizures. Mice were tested for their sensitivity to seizures induced by picrotoxin and NMDA (Research Biochemicals International, Natick, MA). $\mathrm{F}_{2}$ progeny from the cross of two MALS-1 knockout $(\mathrm{KO})$ founders $(+/+,+/-$, or $-/-)$ were used. Picrotoxin and NMDA were dissolved in physiological saline. All drug solutions were freshly prepared and administered by intraperitoneal injection in a volume of $0.1 \mathrm{ml} / 10 \mathrm{gm}$ body weight. After drug administration, mice were observed for $30 \mathrm{~min}$ for the occurrence of clonic seizures.

DNA isolation, genotyping, and microsatellite analysis. Genomic DNA was isolated from mouse tails by proteinase $\mathrm{K}$ digestion and column purification according to the manufacturer's instructions (Qiagen, Valencia, CA). Genotyping of $M A L S-1$ loci was performed as described previously (Misawa et al., 2001). Microsatellite marker flanking sequences and mapping data were obtained from the Mouse Genome Database at The Jackson Laboratory (http://www.informatics.jax.org). Additional mapping data were obtained from the ensemble database (http://www.ensembl.org). PCRs were conducted with AmpliTaq Gold DNA polymerase (PerkinElmer Biosystems, Foster City, CA). Samples were electrophoresed on 3\% metaphor agarose gel (FMC Bioproducts, Rockland, ME) and stained with ethidium bromide. Genotypes were scored by two independent observers blinded to the seizure phenotype.

Single nucleotide polymorphism identification. Using information from the mouse ensemble database, in particular the physical mapping of mouse chromosome 10 (Puttagunta et al., 2000), we identified genes or expressed sequence tags that map near the jams1 (juvenile audiogenic monogenic seizures) locus. To identify single nucleotide polymorphisms (SNPs), PCR primers were designed to amplify exons from 129 and CAST/Ei genomic DNA, and the nucleotide sequences were compared between the two strains. Genotyping recombinant mice determined SNP genetic positions relative to Massachusetts Institute of Technology (MIT) markers.

Brainstem auditory-evoked response testing. All procedures were in accordance with the regulations of the University of California at San Francisco Animal Care Committee. Each mouse was anesthetized by intraperitoneal injection of $90-120 \mathrm{mg} / \mathrm{kg}$ ketamine and $5-10 \mathrm{mg} / \mathrm{kg}$ xylazine. Body temperature was maintained with the help of a heating pad. Silver wires were inserted under the skin at the vertex and near the mastoid for each ear. The ground electrode was placed at the vertex, the active electrode at the ear receiving sound stimulation, and the reference electrode at the unstimulated ear.
Table 1. Association of MALS-1 with juvenile audiogenic seizure susceptibility in Black Swiss mice

\begin{tabular}{llcc} 
MALS-1 genotype & Age & $\begin{array}{l}\text { Number of } \\
\text { mice tested }\end{array}$ & $\begin{array}{l}\text { Number of } \\
\text { mice with seizure }\end{array}$ \\
\hline Wild type $(+/+)$ & $21 \mathrm{~d}$ & 25 & $17(68 \%)$ \\
Heterozygote $(+/-)$ & $21 \mathrm{~d}$ & 41 & $3(7 \%)$ \\
Homozygote $(-/-)$ & $21 \mathrm{~d}$ & 16 & $0(0 \%)$ \\
Wild type $(+/+)$ & $16 \mathrm{~d}$ & 11 & $8(73 \%)$ \\
Heterozygote $(+/-)$ & $16 \mathrm{~d}$ & 15 & $1(7 \%)$ \\
Homozygote $(-/-)$ & $16 \mathrm{~d}$ & 6 & $0(0 \%)$ \\
Wild type $(+/+)$ & 12 weeks & 7 & $0(0 \%)$ \\
Total & & 121 & $29(24 \%)$ \\
\hline
\end{tabular}

$\overline{\mathrm{F}_{2} \text { progeny from an initial MALS-1 KO chimera and Black Swiss intercross were }}$ subjected to an identical sound stimulus, and the percentage of animals seizing was scored.

Recordings were made in a sound-isolating chamber (Industrial Acoustics Company, Bronx, NY). Monopolar clicks from an electric speaker (Stax, Iruma-Gun, Japan) of $0.2 \mathrm{msec}$ duration, $20 \mathrm{~Hz}$ rate, and variable intensity were delivered via a tube inserted into the outer ear canal. The speakers were calibrated with a Bruel and Kjaer sound level meter. The signal measured by the electrodes was filtered to lie between 100 and $1000 \mathrm{~Hz}$ and sampled at $20 \mathrm{kHz}$. For any particular sound intensity, the average of 500 responses, each measured from 0 to $15 \mathrm{msec}$ after the click onset, was determined. The average waveforms generated as the sound pressure level was lowered in $10 \mathrm{~dB}$ and then $5 \mathrm{~dB}$ steps were compared to estimate visually the threshold for which an auditory brainstem response (ABR) could be observed. Most mice were tested in only one ear, but some were tested in both and some on two different days to check the consistency of our procedures.

\section{RESULTS}

\section{Identification of a mouse strain, Black Swiss, with a heretofore unrecognized susceptibility to audiogenic seizures}

The seizure susceptibility of Black Swiss mice was discovered serendipitously during our breeding of the $M A L S$ - $1 \mathrm{KO}$ (Misawa et al., 2001). Generating these knock-out mice involved an initial cross between Black Swiss females and chimeric 129 males, which harbored the MALS-1 KO allele. In analyzing the $\mathrm{F}_{2}$ cross, we noted that $24 \%$ of the offspring seized when exposed to noxious sound at 2-4 weeks after birth (Table 1). Genotyping these $\mathrm{F}_{2}$ mice revealed that the seizures occurred in $25(69 \%)$ mice that were homozygous wild-type for the MALS-1 locus, in four (7\%) of the heterozygous mice and none of the $M A L S-1$ knock-out mice.

We also investigated whether this susceptibility to seizures was evident in other experimental models of seizure induction. $\mathrm{F}_{2}$ progeny from the $M A L S-1 \mathrm{KO}$ founders were exposed to intraperitoneal injections of either picrotoxin or NMDA at doses known to induce seizures in mice (Gershenfeld et al., 1999) and were observed for seizures during a 30 min interval (Table 2). We noted no difference in ictal responses to these neurotoxins between the wild-type and homozygous knock-out animals, suggesting that the observed seizure susceptibility may be specific to audiogenic seizures.

The pattern of inheritance of seizure susceptibility in the $\mathrm{F}_{2}$ progeny suggested that either the lack of $M A L S-1$ gene or a closely linked locus confers sensitivity to audiogenic seizures. To address this, we tested for susceptibility to audiogenic seizures in the two parental strains. We found that juvenile Black Swiss mice $(n>100)$ are uniformly susceptible to audiogenic seizures, whereas the 129 mice are resistant ( 0 of 20 ). To analyze the 
Table 2. MALS-1 genotype does not influence drug-induced seizures in Black Swiss mice

\begin{tabular}{llll} 
MALS-1 genotype & $\begin{array}{l}\text { Treatment } \\
\text { (mg/kg, i.p.) }\end{array}$ & $\begin{array}{l}\text { Seizures } \\
\text { (number seized } \\
\text { over total) }\end{array}$ & $\begin{array}{l}\text { Latency } \\
\text { (sec } \pm \text { SEM) }\end{array}$ \\
\hline Wild type $(+/+)$ & Picrotoxin (8) & $5 / 5$ & $198 \pm 25$ \\
Heterozygote $(+/-)$ & Picrotoxin (8) & $7 / 7$ & $226 \pm 30$ \\
Homozygote $(-/-)$ & Picrotoxin (8) & $7 / 7$ & $238 \pm 51$ \\
Wild type $(+/+)$ & NMDA (120) & $3 / 5$ & $217 \pm 44$ \\
Heterozygote $(+/-)$ & NMDA (120) & $12 / 18$ & $230 \pm 20$ \\
Homozygote $(-/-)$ & NMDA (120) & $5 / 7$ & $189 \pm 12$
\end{tabular}

$\overline{\text { Juvenile } \mathrm{F}_{2} \text { progeny from an initial MALS-1 KO chimera and Black Swiss intercross }}$ were given intraperitoneal injections of varying doses of picrotoxin or NMDA and observed for time to seizure onset.

inheritance of audiogenic seizures in Black Swiss mice, we bred them to wild-type 129 mice. None of the $F_{1}$ progeny seized in response to the audiogenic stimulus, indicating that the seizure resistance was dominant in this cross. Interestingly, in analysis of the $\mathrm{F}_{2}$ intercross juvenile mice, we observed that $\sim 25 \%$ of these progeny demonstrated audiogenic seizures, consistent with a simple autosomal recessive trait. Together, these studies revealed that this seizure susceptibility is a previously undocumented trait of Black Swiss mice, and that the susceptibility locus maps close to the $M A L S$-1 gene.

\section{The jams1 locus maps to a $1.6 \mathrm{cM}$ region on mouse chromosome 10}

The mouse MALS-1 gene is located on chromosome 10 between markers D10Mit264 and D10Mit237, and our initial studies showed that seizure susceptibility in Black Swiss mice was linked to this region. To map the seizure susceptibility locus, we identified informative simple sequence length polymorphism (SSLP) markers spanning a $40 \mathrm{cM}$ region of chromosome 10. A group of 114 juvenile $\mathrm{F}_{2}(129 \times \mathrm{BS})$ mice was subjected to the seizureinducing audiogenic stimulus and genotyped. The marker D10Mit228 segregated most closely with seizure susceptibility; all 31 mice that were homozygous for the Black Swiss allele seized, whereas none of the 83 mice that were either heterozygous or homozygous for the 129 allele at this position seized (Table 3). Based on the analysis of this initial cross, markers D10Mit186 and D10Mit264 delimit the critical region (Fig. 1A). The calculated distance between these two flanking markers was $8.8 \pm 2.4 \mathrm{cM}$ in this intercross and $10 \mathrm{cM}$ as established by the Mouse Genome Database (http://www.informatics.jax.org) (Blake et al., 2000). We have designated this locus jams1, for juvenile audiogenic monogenic seizures (nomenclature approved by the International Committee on Standardized Genetic Nomenclature for Mice).

For fine mapping jams1, the 129 strain is not an optimal mating partner, because most of the SSLP markers characterized previously are not polymorphic with Black Swiss in the critical region on chromosome 10 . To identify a more advantageous breeding partner and to test whether the seizure gene on chromosome 10 is penetrant in another strain, we mated the Black Swiss mice with the inbred strain CAST/Ei derived from Mus musculus castaneus. The latter strain is useful for this analysis because it is genetically distant from Black Swiss (Beck et al., 2000). We first tested 3-week-old CAST/Ei for audiogenic seizure susceptibility and found them to be seizure resistant $(n=40)$. We then tested 21-d-old $\mathrm{F}_{1}(\mathrm{CAST} / \mathrm{Ei} \times \mathrm{BS})$ progeny and found them to be similarly seizure resistant $(n=120)$. This suggested that the seizure resistance of CAST/Ei mice is dominant in this cross.
We bred second-generation offspring to analyze segregation of this phenotype with markers on chromosome 10. We studied 301 $\mathrm{F}_{2}$ and $518 \mathrm{~N}_{2}$ progeny and found that $22 \%$ of the $\mathrm{F}_{2}$ mice and $51 \%$ of the $\mathrm{N}_{2}$ mice demonstrated audiogenic seizures. These offspring were then all screened with informative SSLP markers as well as selective SNPs spanning the critical region identified in the initial cross. We first found that $90 \%$ of mice homozygous for Black Swiss across the $8 \mathrm{cM}$ jams 1 locus seized, whereas only $3.7 \%$ of mice heterozygous in this region seized. This indicates a high penetrance of the jams1 mutation. Detailed analysis of recombinants narrowed the jams 1 locus to an $\sim 1.6 \mathrm{cM}$ region between an SNP in the gene basigin (Bsg) and marker D10Mit140. Marker D10Mit22 was not separable with jams1 in examining $\sim 1100$ meioses. The proximal border of the interval was defined by two obligate and nonobligate recombinants between Bsg and D10Mit22, whereas one obligate and four nonobligate recombinants define the distal boundary between D10Mit22 and D10Mit140 (Fig. 1B). To prevent false-positive and -negative animals from obscuring identification of the jams1 locus, we have bred all recombinant animals back to Black Swiss or $\mathrm{F}_{1}(\mathrm{BS} \times$ $\mathrm{CAST} / \mathrm{Ei}$ ) adults and analyzed the genotype and seizure susceptibility of these backcrossed offspring. This approach enabled us to confirm the reproducibility of the phenotype for the recombinant mice and hence the boundaries for this interval (data not shown).

\section{Susceptibility to audiogenic seizures is developmentally regulated in Black Swiss mice}

Developmental regulation is common in human idiopathic generalized epilepsies; therefore, its presence in mouse models may suggest a mechanistic link. We have observed that Black Swiss mice display a developmentally regulated susceptibility to audiogenic seizures. Figure 2 demonstrates that Black Swiss mice are most susceptible to seizures as juveniles and that this susceptibility declines in adulthood. All of the 14- to 21-d-old mice seized, and the time to seizure onset was $<30 \mathrm{sec}$. However, none of the 7-d-old mice seized. By $42 \mathrm{~d}$ of age, only $75 \%$ seized, and two-thirds of these animals did not begin to seize until $90 \mathrm{sec}$ after the onset of the $108 \mathrm{~dB}$ auditory stimulus. By adulthood, $<10 \%$ of mice seized, and the few that convulsed did not begin until 2 min of continuous sound exposure.

\section{Hearing loss does not influence seizure susceptibility or the developmental regulation of seizures in Black Swiss mice}

To address a possible role for hearing loss in the audiogenic seizure susceptibility of mice possessing the mutant jams1 locus, we first tested ABR thresholds in the two parental strains. CAST/Ei adult mice have an ABR threshold $(26 \pm 9 \mathrm{~dB})$ that is similar to thresholds reported previously for this strain (Zheng et al., 1999). Additionally, the hearing threshold is similar to those observed for another mouse strain, BALB/cAnNHsd (BALB/c), that has been reported to have normal hearing. In comparison, Black Swiss mice have increased thresholds both at 3 weeks of age (when seizure susceptibility is tested) and as adults $(p<0.01)$ (Fig. 3). To address whether hearing loss influences seizure susceptibility, we have tested ABR thresholds of $\mathrm{F}_{2}$ and $\mathrm{N}_{2}$ adult mice and found the average thresholds to be between those for the two parental strains $(50 \pm 10 \mathrm{~dB}$ and $42 \pm 8 \mathrm{~dB})$. Importantly, the hearing thresholds in these hybrids were nearly identical between seizing and nonseizing mice $(p>0.5)$, suggesting that hearing loss does not play a role in seizure susceptibility in these mice. 
Table 3. Linkage of audiogenic seizures with markers on chromosome 10

\begin{tabular}{|c|c|c|c|c|c|c|}
\hline Marker & D10Mit88 & D10Mit186 & D10Mit228 & D10Mit264 & $M A L S-1$ & D10Mit237 \\
\hline $\mathrm{cM}$ & 29 & 40 & 47 & 50 & 58 & 67.5 \\
\hline Rec Fx. $(\Xi)$ & 0.13 & 0.036 & 0.0 & 0.096 & 0.131 & 0.228 \\
\hline$\chi^{2}$ & 36.5 & 93.9 & N.A. & 66.5 & 53.7 & 23.7 \\
\hline
\end{tabular}

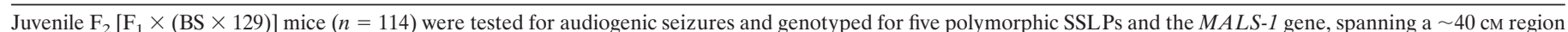

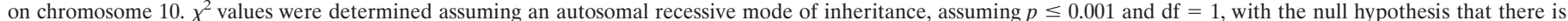

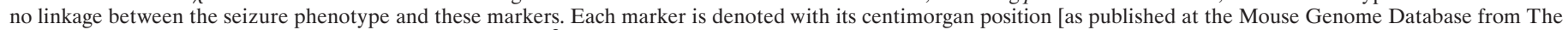
Jackson Laboratory (http://www.informatics.jax.org)], the $\chi^{2}$ values, and the recombination fraction (Rec. Fx.), $\Xi$, listed above.

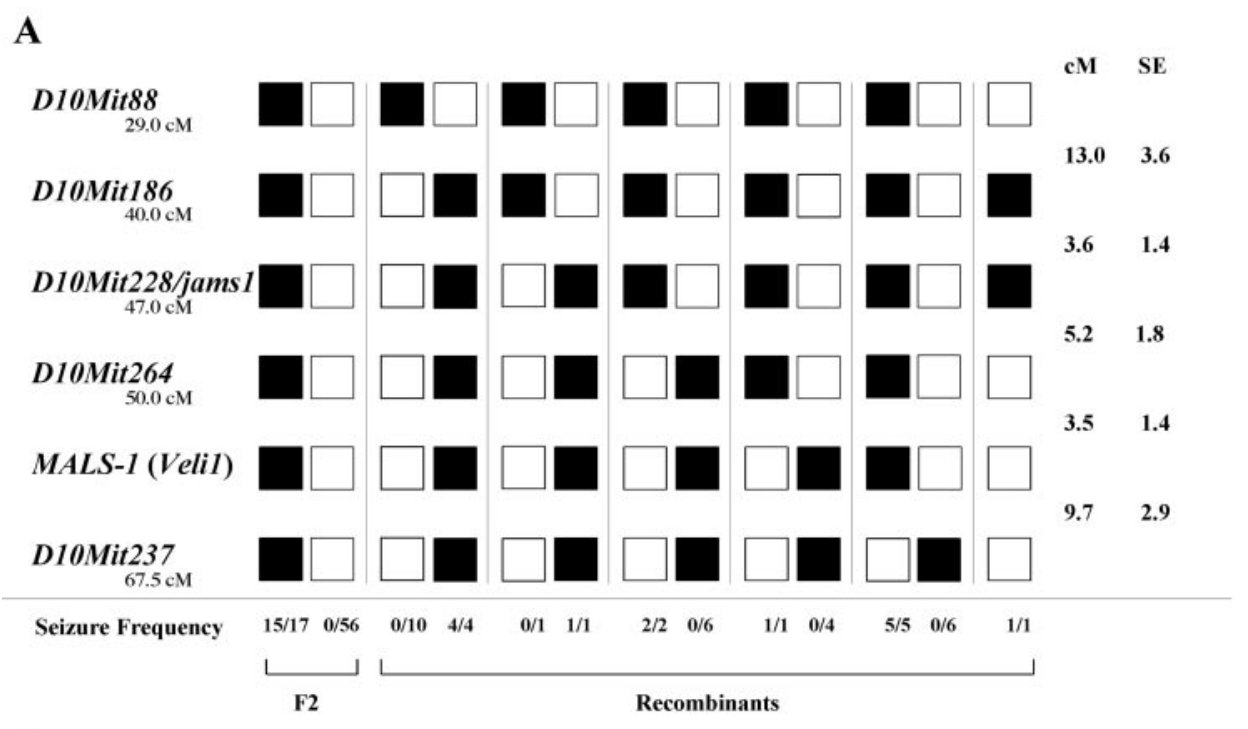

$\mathbf{B}$

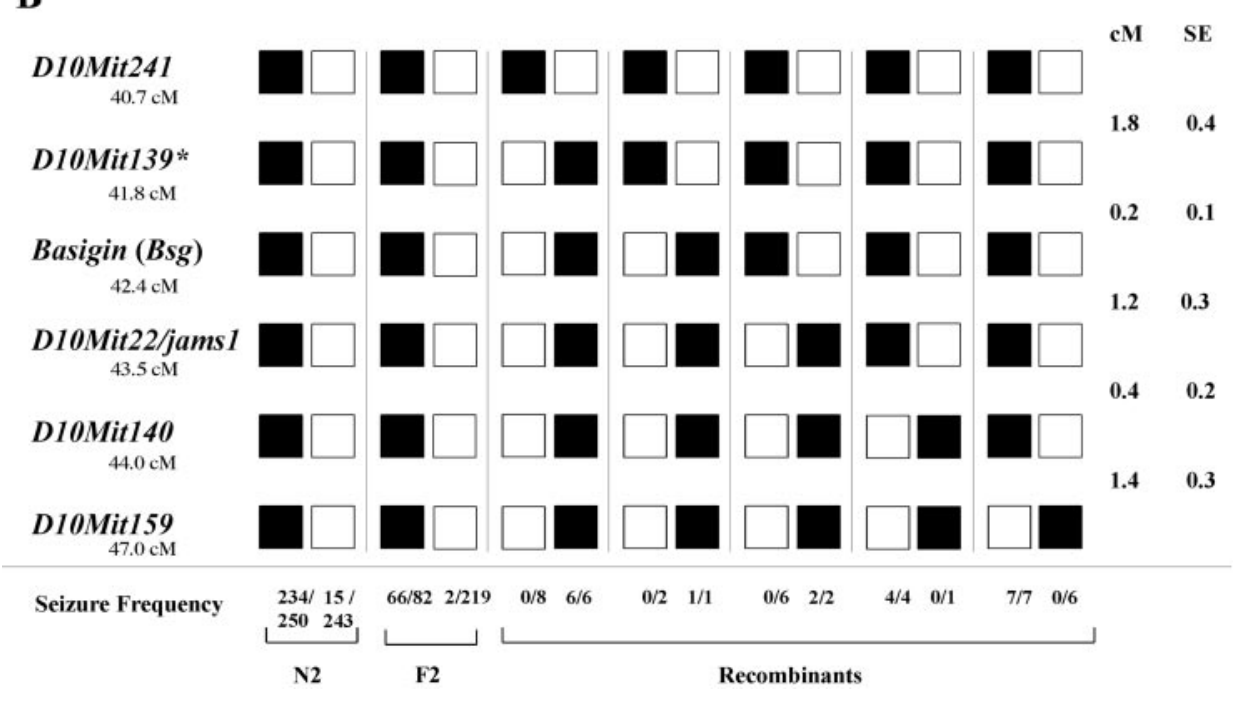

Figure 1. Defining a $1.6 \mathrm{cM}$ jams1 locus. The segregation pattern of the microsatellite markers most closely linked to audiogenic seizures is shown. Black squares indicate markers homozygous for BS alleles. White squares indicate homozygous alleles from the seizure-resistant strain in the cross (CAST/Ei or 129) or for heterozygous alleles. For seizure frequency, the denominator is total mice with given genotype; the numerator is the number seized. $A$, jams1 cosegregates with marker D10Mit228 in an intraspecific $\mathrm{F}_{2}$ cross between Black Swiss and $129(n=$ 114). $B$, In $\mathrm{F}_{2}$ and $\mathrm{N}_{2}$ crosses between Black Swiss and CAST/Ei, jams1 did not segregate from marker D10Mit22 $(n=$ 794). *We have listed data for D10Mit139 in this figure; however, we have not observed recombination between this marker and D10Mit260 or D10Mit175 in these crosses (data not shown).

Finally, we asked whether the adult-onset resistance of Black Swiss mice to audiogenic seizures is attributable to poor hearing. To address this, we tested $\mathrm{N}_{2}$ progeny $\left(\mathrm{F}_{1} \times \mathrm{BS}\right)$ for seizure susceptibility at 3 weeks and again as adults. ABR thresholds were then determined in these adult mice. As shown in Figures 3 and 4, the ABR thresholds for mice that reseized as adults were not significantly different from those that lost their audiogenic seizure susceptibility $(p>0.6)$. Although there was one mouse with a high threshold that did not reseize, many adult $\mathrm{N}_{2}$ mice became resistant to audiogenic seizures despite retaining a nearnormal hearing threshold. This suggests that, in this model of audiogenic seizures, age-related hearing loss does not significantly contribute to the developmental nature of the seizure phenotype.

\section{DISCUSSION}

Genetic analysis of inherited epilepsy syndromes is a powerful tool for dissecting the basic mechanisms underlying seizure susceptibility and propagation. We have identified a highly penetrant sensitivity to audiogenic seizures in Black Swiss mice. These mice are susceptible to seizures as juveniles and resistant as adults, similar to the classic developmental course for this syndrome in 


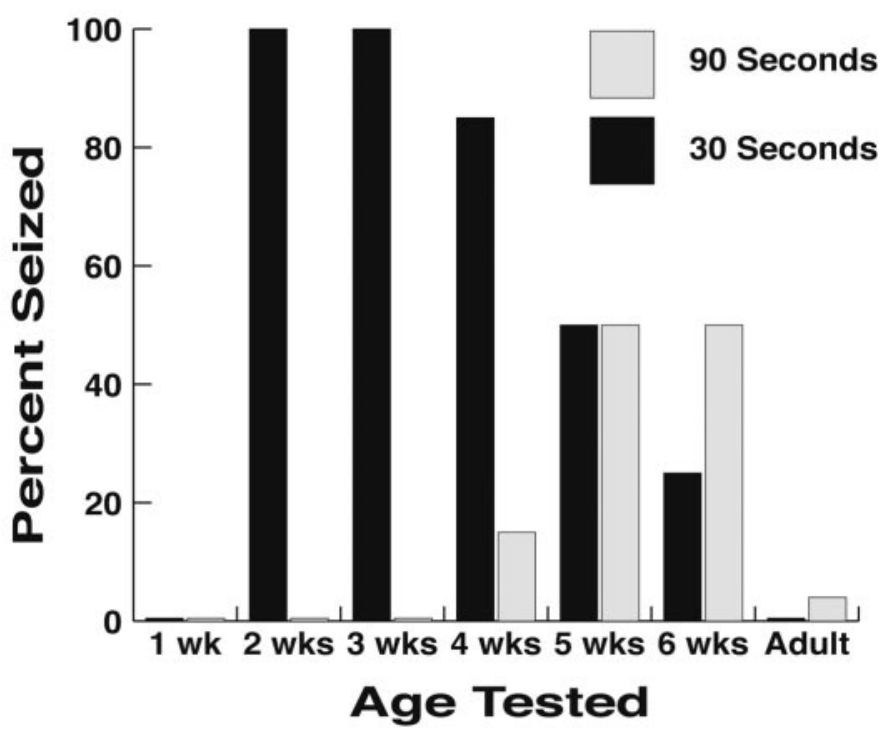

Figure 2. Black Swiss mice display an age-dependent susceptibility to seizures. Mice were exposed to an auditory stimulus (see Materials and Methods). The percentage of mice that seized and time to onset of seizure [30 sec (ם) or $90 \mathrm{sec}(\square)]$ are noted.

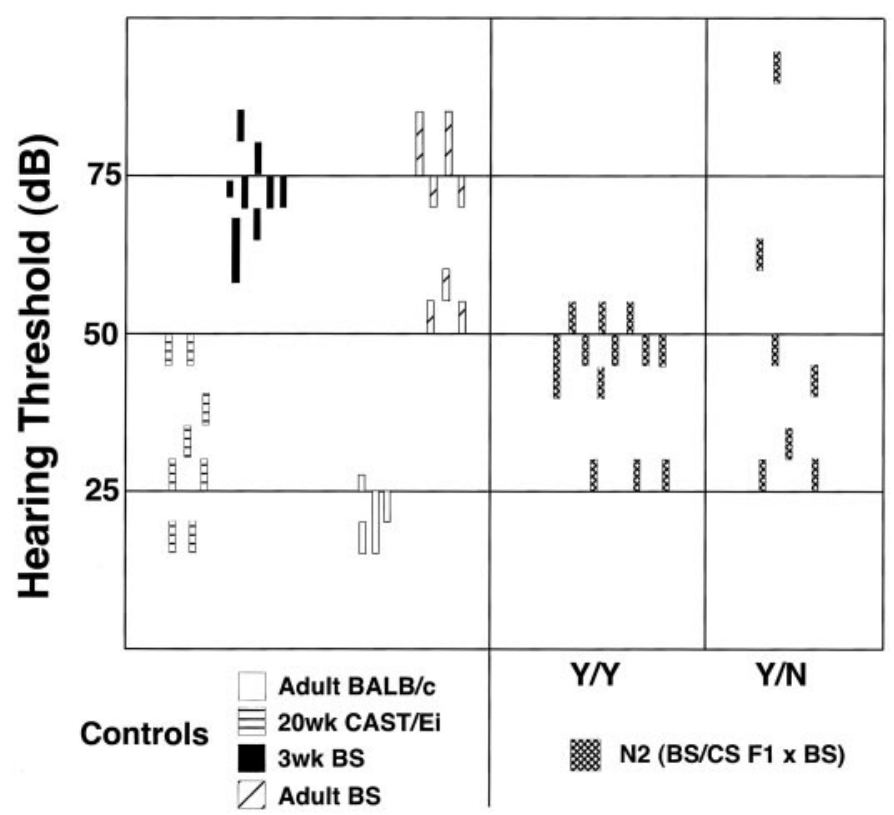

Figure 3. Seizure susceptibility of backcrossed Black Swiss mice is independent of hearing thresholds. $A$, Auditory brainstem response thresholds were measured from BALB/c, CAST/Ei, Black Swiss, and various BS $\times$ CAST/Ei progeny $\left(\mathrm{F}_{2}\right.$ and $\left.\mathrm{N}_{2}\right) . \mathrm{F}_{2}$ and $\mathrm{N}_{2}$ mice were tested twice for seizure susceptibility, at $21 \mathrm{~d}$ and 4 months of age. Those that seized at both ages are designated $\mathrm{Y} / \mathrm{Y}$, and those that seized at $21 \mathrm{~d}$ but not at 4 months are designated $\mathrm{Y} / \mathrm{N}$. These results suggest that adult onset hearing loss does not correlate with loss of seizure susceptibility.

DBA/2J mice and certain other strains (Deckard et al., 1976; Neumann and Collins, 1991; Banko et al., 1997). However, unlike these other strains, juvenile audiogenic seizure susceptibility in Black Swiss mice is inherited as a simple autosomal recessive trait. This mode of inheritance occurs in two distinct genetic backgrounds, 129 and CAST/Ei, suggesting that this trait is highly penetrant as an independent locus. This will facilitate cloning of
A

A Adult CAST/Ei

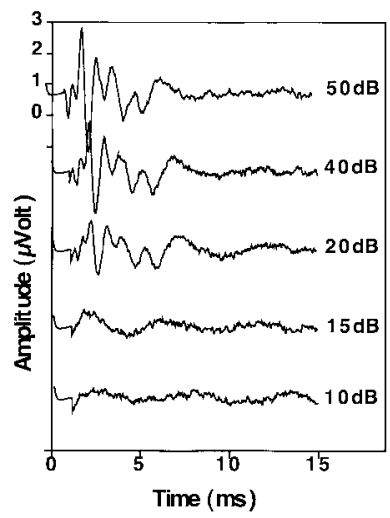

C

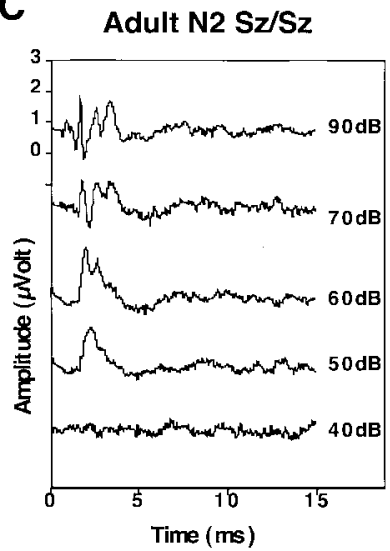

B 3 wk old Black Swiss

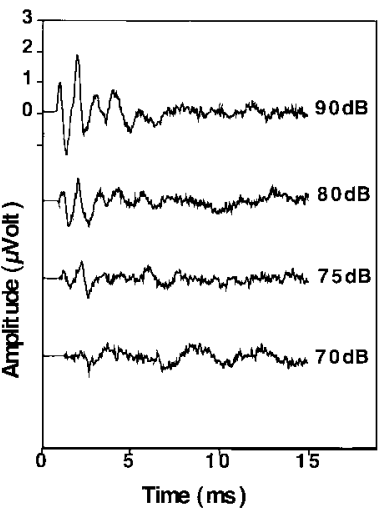

D

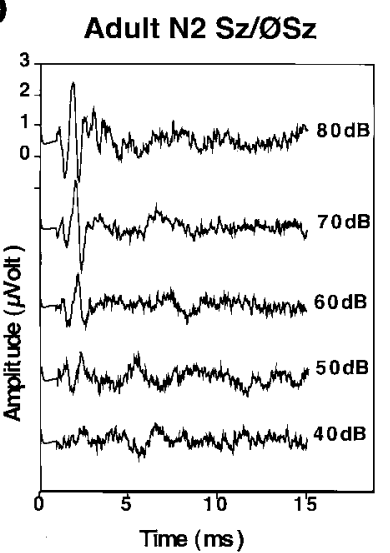

Figure 4. ABR tracings of Black Swiss, CAST/Ei, and $\mathrm{N}_{2}$ progeny. Shown are representative tracings of auditory brainstem responses to clicks of different sound intensities for the parental strains and $\mathrm{N}_{2}$ progeny. $A, \mathrm{~A} 3$-week-old Black Swiss mouse. $B$, An adult CAST/Ei mouse. $C$, An $\mathrm{N}_{2}$ mouse that seized both as a 21-d-old juvenile and as a 150-d-old adult $(S z / S z)$. $D, \mathrm{An}_{2}$ mouse that did not seize as an adult $(\mathrm{Sz} / \emptyset \mathrm{Sz})$.

the responsible gene and may indicate that this gene is central to the underlying biology of audiogenic seizure propagation.

Efforts to identify the genes responsible for juvenile audiogenic seizures have been hampered by complex genetics, including evidence for imprinting (Neumann and Collins, 1991) and the influence of many loci. The three main loci identified in DBA mice (Asp 1-3) are on chromosomes 12, 4, and 7 (Neumann and Seyfried, 1990; Neumann and Collins, 1992), which are all different from the jams 1 locus. Single gene mutations that cause audiogenic seizures in adult mice have been described recently. Audiogenic seizures in the X-linked serotonin 5-HT2c receptor mutant mice (Brennan et al., 1997) begin at $75 \mathrm{~d}$ of age and become fully penetrant at $120 \mathrm{~d}$. In addition, the Frings mouse has a susceptibility to audiogenic seizures that is evident at $21 \mathrm{~d}$ and persists into adulthood (Skradski et al., 1998), which is in contrast to the juvenile susceptibility in DBA/2J and Black Swiss mice. The gene mutated in Frings mice, mass1, has been identified recently (Skradski et al., 2001). It will be interesting to learn how mass 1 may interact with jams1, and why seizures associated with jams1 abate as the animals mature.

The pathogenesis of audiogenic seizures is uncertain. Previous work has shown that rodents can be primed to develop audiogenic seizures by lesions that impair hearing during cochlear development, such as traumatizing the tympanic membrane or instilling 
ototoxic drugs. Consistent with this, some rodent strains sensitive to audiogenic seizures, such as $\mathrm{DBA} / 2 \mathrm{~J}$ and $\mathrm{LP} / \mathrm{J}$ mice and genetically epilepsy-prone rat-3,9 rats, have elevated ABR thresholds during the period of maximum susceptibility. Additionally, we find that Black Swiss mice have elevated hearing thresholds as both juveniles and adults. Because seizure susceptibility in Black Swiss mice is inherited at a single locus, we were able to test whether the elevated hearing threshold in this strain explains their seizure sensitivity. However, our experiments show no correlation between hearing and seizure susceptibility. Although we cannot completely exclude a role for hearing loss in audiogenic seizures, our data suggest that the jams1 mutation does not influence hearing threshold. Furthermore, we find that the loss of seizure sensitivity in adult mice cannot simply be explained by age-related hearing loss, but rather that the jams1 mutation confers a susceptibility to audiogenic seizures during a discreet period in the animal's life. This may indicate that the mechanisms of developmental regulation of the jams1-induced audiogenic seizures are relevant to human disease, because many human idiopathic epilepsies, although not induced by audiogenic stimuli, are also developmentally regulated.

Cloning the jams1 mutant allele may be facilitated by evaluation of candidate genes. Within the critical interval on mouse chromosome 10 is the gene for cystatin $\mathrm{B}$, which is mutated in Baltic progressive myoclonic epilepsy (EPM1) (Pennacchio et al., 1996). However, we found that the mRNA sequence and expression level of cystatin B in Black Swiss mice are identical to that of 129 mice (data not shown). Ion channels and neurotransmitter receptors are reasonable candidates for seizure-causing alleles, but there are currently no identified candidate ion channel subunits within the defined interval. However, mouse mutants jittery and hesitant, two alleles of an unidentified gene, have been mapped to nearly the exact same region of mouse chromosome 10, between Bsg and D10Mit140. Jittery is lethal before mating; however, surviving homozygotes have audiogenic and stimulusinduced seizures as well as progressive ataxia (Kapfhamer et al., 1996). A viable allele, hesitant, has been described that does not have seizures but still has mild ataxia. It is possible that our mice represent another allele of this locus.

Interestingly, much of the critical region identified here is syntenic to human chromosome 19p13.3 (Puttagunta et al., 2000). Two disorders have been mapped to this region: febrile seizures (FEB2) and a nonprogressive form of ataxia found in the Cayman Islands (Nystuen et al., 1996). The locus for febrile seizures has been identified in more than one pedigree by independent investigators and overlaps significantly with the region syntenic to jams1 (Johnson et al., 1998). Because both febrile and audiogenic seizures are thought of as generalized seizures, it is possible that these represent homologous diseases in different species. Cloning of jams1 will allow for a candidate gene approach for these human disorders and may provide important insight into the general mechanisms of developmentally regulated epilepsies.

\section{REFERENCES}

Banko ML, Allen KM, Dolina S, Neumann PE, Seyfried TN (1997) Genomic imprinting and audiogenic seizures in mice. Behav Genet 27:465-475.
Beck JA, Lloyd S, Hafezparast M, Lennon-Pierce M, Eppig JT, Festing MF, Fisher EM (2000) Genealogies of mouse inbred strains. Nat Genet 24:23-25.

Blake JA, Eppig JT, Richardson JE, Davisson MT (2000) The Mouse Genome Database (MGD): expanding genetic and genomic resources for the laboratory mouse. The Mouse Genome Database Group. Nucleic Acids Res 28:108-111.

Brennan TJ, Seeley WW, Kilgard M, Schreiner CE, Tecott LH (1997) Sound-induced seizures in serotonin 5-HT2c receptor mutant mice. Nat Genet 16:387-390.

Deckard BS, Lieff B, Schlesinger K, DeFries JC (1976) Developmental patterns of seizure susceptibility in inbred strains of mice. Dev Psychobiol 9:17-24.

Gershenfeld HK, Neumann PE, Li X, St Jean PL, Paul SM (1999) Mapping quantitative trait loci for seizure response to a $\mathrm{GABA}_{\mathrm{A}}$ receptor inverse agonist in mice. J Neurosci 19:3731-3738.

Hall C (1947) Genetic differences in fatal audiogenic seizures. J Hered 6:3-6.

Johnson EW, Dubovsky J, Rich SS, O’Donovan CA, Orr HT, Anderson VE, Gil-Nagel A, Ahmann P, Dokken CG, Schneider DT, Weber JL (1998) Evidence for a novel gene for familial febrile convulsions, FEB2, linked to chromosome $19 \mathrm{p}$ in an extended family from the Midwest. Hum Mol Genet 7:63-67.

Kapfhamer D, Sweet HO, Sufalko D, Warren S, Johnson KR, Burmeister M (1996) The neurological mouse mutations jittery and hesitant are allelic and map to the region of mouse chromosome 10 homologous to 19p13.3. Genomics 35:533-538.

Misawa H, Kawasaki Y, Mellor J, Sweeney N, Jo K, Nicoll RA, Bredt DS (2001) Contrasting localizations of MALS/LIN-7 PDZ proteins in brain and molecular compensation in knockout mice. J Biol Chem 276:9264-9272.

Neumann PE, Collins RL (1991) Genetic dissection of susceptibility to audiogenic seizures in inbred mice. Proc Natl Acad Sci USA 88:5408-5412.

Neumann PE, Collins RL (1992) Confirmation of the influence of a chromosome 7 locus on susceptibility to audiogenic seizures. Mamm Genome 3:250-253.

Neumann PE, Seyfried TN (1990) Mapping of two genes that influence susceptibility to audiogenic seizures in crosses of $\mathrm{C} 57 \mathrm{BL} / 6 \mathrm{~J}$ and DBA/2J mice. Behav Genet 20:307-323.

Noebels JL (1999) Single-gene models of epilepsy. Adv Neurol 79: 227-238.

Nystuen A, Benke PJ, Merren J, Stone EM, Sheffield VC (1996) A cerebellar ataxia locus identified by DNA pooling to search for linkage disequilibrium in an isolated population from the Cayman Islands. Hum Mol Genet 5:525-531.

Pennacchio LA, Lehesjoki AE, Stone NE, Willour VL, Virtaneva K, Miao J, D'Amato E, Ramirez L, Faham M, Koskiniemi M, Warrington JA, Norio R, de la Chapelle A, Cox DR, Myers RM (1996) Mutations in the gene encoding cystatin $\mathrm{B}$ in progressive myoclonus epilepsy (EPM1). Science 271:1731-1734.

Prasad AN, Prasad C, Stafstrom CE (1999) Recent advances in the genetics of epilepsy: insights from human and animal studies. Epilepsia 40:1329-1352.

Puttagunta R, Gordon LA, Meyer GE, Kapfhamer D, Lamerdin JE, Kantheti P, Portman KM, Chung WK, Jenne DE, Olsen AS, Burmeister M (2000) Comparative maps of human 19p13.3 and mouse chromosome 10 allow identification of sequences at evolutionary breakpoints. Genome Res 10:1369-1380.

Ross KC, Coleman JR (2000) Developmental and genetic audiogenic seizure models: behavior and biological substrates. Neurosci Biobehav Rev 24:639-653.

Ryan SG (1999) Ion channels and the genetic contribution to epilepsy. J Child Neurol 14:58-66.

Seyfried TN, Todorova MT, Poderycki MJ (1999) Experimental models of multifactorial epilepsies: the EL mouse and mice susceptible to audiogenic seizures. Adv Neurol 79:279-290.

Skradski SL, White HS, Ptacek LJ (1998) Genetic mapping of a locus (mass1) causing audiogenic seizures in mice. Genomics 49:188-192.

Skradski SL, Clark AM, Jiang H, White HS, Fu YH, Ptacek LJ (2001) A novel gene causing a mendelian audiogenic mouse epilepsy. Neuron 31:537-544.

Zheng QY, Johnson KR, Erway LC (1999) Assessment of hearing in 80 inbred strains of mice by ABR threshold analyses. Hear Res 130:94107. 